\title{
NUEVOS ACTORES SOCIALES EN EL ESCENARIO AUDIOVISUAL
}

\section{Las asociaciones de telespectadores}

\author{
Gloria Rosique Cedillo \\ Doctora Europea. Universidad Complutense de Madrid
}

\begin{abstract}
Since de private channels starting in the Spanish audiovisual sector, the entertainment broadcasting television environment, went through significant changes in their programming. This situation open's the debate of having or not a private or public television, that doesn't comply with the social expectations. This has generated that organizes civil groups as television viewers associations, start actions with the objective to influences in the way of the entertainment contents, bet for the television viewers education and the citizen's participation in the television's subjects.
\end{abstract}

\section{Key words}

Entertainment contents; Televiewier associations; TV agents; Corregulation; Broadcasting television 


\section{Resumen}

A raíz de la entrada de las televisiones privadas al sector audiovisual español, el panorama de los contenidos de entretenimiento de la televisión generalista vivió cambios trascendentales que se vieron reflejados en las parrillas de programación. Esta situación ha abierto la polémica en torno a la disyuntiva de tener o no una televisión, sea pública o privada, que no cumple con las expectativas sociales esperadas. Esto ha motivado a que grupos civiles organizados en asociaciones de telespectadores, emprendan diversas acciones con el objetivo de incidir en el rumbo que los contenidos de entretenimiento vienen tomando, apostando fuertemente por la educación del receptor en relación a los medios audiovisuales, y por la participación ciudadana en torno a los temas televisivos.

\section{Palabras clave}

Contenidos de entretenimiento; Asociaciones de telespectadores, Agentes televisivos; Corregulación; Televisión generalista 
«Il faut donner au téléspectateur non pas ce qu'il aime, mais ce qui' il pourrait aimer ${ }^{1} »$.

Jacques Chancel

(Hérouville, 2001: 41)

\section{La televisión de divertimento}

Herbert Marcuse (1968) ya había dejado ver sus reflexiones en torno al poder de la televisión, preguntándose si realmente se podía diferenciar entre los medios de comunicación de masas como instrumentos de información y diversión, y como medios de manipulación y adoctrinamiento que diseñaban la vida del hombre en relación a su trabajo en las fábricas, como una forma predominante de control social.

Asimismo, tal como lo afirma Giovanni Sartori (1997), la televisión ha ido convirtiendo al homo sapiens, animal simbólico, en un homo videns, donde el telespectador es más un animal vidente inmerso en una cultura predominantemente visual. Este hecho repercute en las nuevas generaciones donde el vídeo-niño aprende y se informa a través de la televisión, reduciéndose a un ser reblandecido que no lee, ve.

Bajo estas concepciones se entreteje igualmente el concepto anticipado de Marshall McLuhan (1967) sobre 'el medio es el mensaje' donde cabe preguntarse si más allá de la influencia que puede llegar a tener en si misma la televisión, somos conscientes del rumbo que van tomando todos aquellos mensajes envueltos en formatos televisivos que llegan a nuestros hogares.

No pasó mucho tiempo en que los ingenieros vislumbraran el negocio tecnológico que podía significar la televisión, donde la importancia radicaba en el hecho de tener al alcance un aparato

\footnotetext{
1 'Es necesario darle al telespectador no sólo lo que le gusta, si no lo que le podría gustar'.
} 
técnicamente capaz de reproducir imágenes que podían ser transmitidas a otros lugares bajo la condición de tener un receptor; en aquella etapa experimental se comenzaban a descubrir sus potencialidades, pero todavía se ignoraban sus alcances ${ }^{2}$.

Una buena parte de los programas que se hacían se basaban en la atención al ciudadano, en los testimonios orales, en la anécdota y, en general, había un predominio de los contenidos populares $^{3}$ donde el radioescucha formaba parte imprescindible de los programas que, posteriormente, fueron adaptados a la televisión.

Aquél modelo de televisión se movía en torno a una regulación unívoca que provenía y se revolvía desde los ámbitos gubernamentales, como representante legítimo del público ${ }^{4}$.

Las primeras apuestas televisivas iban encaminadas al reforzamiento del concepto de la 'familia', vendiendo la idea del televisor como un aparato para el hogar y que, gracias a la propia imagen que le forjó la publicidad, desde sus comienzos, fue percibido como un electrodoméstico interclasista, de confort y de relativo prestigio para todos, lo que ayudó a su consumo masivo (Laffond, 2005).

La evolución de los contenidos de entretenimiento en España estuvo condicionada por factores socio-políticos que constituyeron el precedente de una televisión que, al paso de los años, se convertiría en el medio de comunicación más influyente y poderoso de la sociedad moderna, lo cual constituiría una problemática social para ciertos sectores de la sociedad civil.

El primer factor determinante para los contenidos de la televisión en España fue la ruptura del monopolio estatal de Televisión Española, donde había predominado la hegemonía televisiva

\footnotetext{
${ }^{2}$ Los Hermanos Lumière, inventores del cine, definieron la televisión, en sus inicios, como "una invención sin futuro". (Jost, 2002: 135).

${ }^{3}$ El año de 1972 queda marcado en la historia de la televisión en España ya que es en esta fecha cuando tiene lugar la primera proyección a nivel internacional de la Radiotelevisión Española, mediante la colaboración de la Organización de Televisiones Iberoamericanas (OTI).

${ }^{4}$ En esos primeros años, fueron excepcionales los casos en que la sociedad civil levantó la voz o se organizó para protestar o buscar influir en los contenidos que se proyectaban en pantalla. Aunque la programación era indiferenciada y se transmitía en horarios según el interés general del gran público, apenas divididos por sexo y edad, lo cierto es que se trataba de una 'televisión familiar', en donde los contenidos no se consideraran nocivos para alguno de los públicos.
} 
franquista centralizada, que se movía en torno a intereses de control informativo, de ahí que "el modelo televisivo estaba encaminado más a la evasión a través del entretenimiento masivo, que a la manipulación" (Laffond, 2005: 2777-278).

Ya en 1989, una década después del Pacto de Moncloa, se abrió el espectro televisivo a la gestión privada, concediendo tres licencias de televisión para emitir en abierto, Antena 3, Telecinco y Canal Plus 5 . Esta apertura significó cambios a nivel global en las estructuras de la televisión pública que desestabilizaron su programación, marcando así el inicio de su endeudamiento ${ }^{6}$.

La televisión pública comenzó a jugar bajo las reglas que las nuevas cadenas le impusieron: contraprogramaciones, lucha por la audiencia, mimetismo en las parrillas de programación, y una mínima oferta para los telespectadores. Se conformaron así, las líneas de ejercicio diario de todo el sistema.

De esta manera, en la década de los 90's, el panorama de los contenidos se torna desolador ${ }^{7}$. La 'telerealidad', primero en su formato de talk show y después con sus reality show ${ }^{8}$, comienza a adueñarse de los espacios programáticos. Estos programas llegaron acompañados de lo que muchos han denominado como 'telebasura', es decir, contenidos que se apoyan en lo espectacular haciendo uso del morbo, la violencia y el voyeurismo; macrogénero que, a través de sus historias enfocadas a atraer a los grandes públicos, se basa en remover los instintos más básicos del hombre.

La 'telerealidad' llega a las pantallas y se extiende al resto de la parrilla de programación, contagiando a géneros que, por su naturaleza, parecían imposibles de transgredir, como es el caso de

\footnotetext{
${ }^{5}$ En el caso de esta cadena, sólo emitía algunas horas en abierto, siendo en su mayoría un servicio de pago.

${ }^{6}$ A partir de 1990, Radio Televisión Española (RTVE) sufrió una alteración esencial: su audiencia comenzó a bajar, como respuesta a la apertura en la oferta televisiva de las privadas, al mismo tiempo que, de un superávit que llegó a alcanzar los 27.000 millones de pesetas (162 mil euros), en 1987, pasó en 1990 a un déficit que no dejó de crecer hasta llegar en 1998, a unas previsiones de unos 140.000 millones de pesetas (841 mil euros)' (Reig, 1998: 50).

${ }^{7}$ Al respecto, Umberto Eco expone: “Un signo de distinción es no salir en televisión” (Eco, 2003).

${ }^{8}$ En el año de 1996, la 'Comisión Especial sobre contenidos televisivos' del Senado, consideraba que los 'reality show' eran los programas que estaban siendo mayor objeto de controversia (Senado, 1996: 134).

9 'Una forma de hacer televisión caracterizada por explotar el morbo, el sensacionalismo y el escándalo, como soportes de atracción a la audiencia, y por el enfoque distorsionado al que recurre para tratar asuntos y personajes' ('Manifiesto contra la 'Telebasura': 1997).
} 
los telediarios, convirtiendo la televisión en un espacio cada vez más lúdico, donde las fronteras entre los géneros televisivos parecen difuminarse.

Al respecto, Pierre Bourdieu dice: “(...) impulsada por la búsqueda de una audiencia lo más amplia posible, ha llevado a la televisión a ser un reducto de discursos xenófobos donde aparecen personajes esperpénticos" (Bourdieu en Díaz, 1999: 38).

Otro género igualmente polémico y destacable en la oferta programática española lo constituye los 'programas del corazón', que tienen por objetivo el mantener informada a la audiencia de la vida de 'los famosos'.

Este género denominado 'crónica rosa' no sólo ocupa una gran parte de los espacios de las parrillas de televisión, sino que se también se extiende a los principales programas contenedores matinales enfocados al público femenino, dando así la sensación de saturación de este género. Este abuso por emitir determinados contenidos puso en cuestión aspectos normativos trascendentales, entre otros, el de la adecuada protección de la audiencia juvenil e infantil (Prieto, 1994: 17).

Un estudio del Centro de Investigaciones Sociológicas (CIS, 2003) sobre la valoración de los telespectadores con relación a la televisión, arrojó que la mayoría de los encuestados consideraban que la televisión en España era bastante entretenida pero de mal gusto, sólo una minoría la que la consideró formativa.

Tabla 1:

'Valoraciones sobre la televisión en España'

\begin{tabular}{|c|c|c|c|l|c|c|}
\hline Categorías & \multicolumn{6}{|c|}{ Valoraciones en porcentajes } \\
\hline & Muy & Bastante & Regular & Poco & Nada & $\begin{array}{c}\text { No } \\
\text { Contestó }\end{array}$ \\
\hline Entretenida & 7,4 & 39,4 & 15,8 & 28,5 & 8,2 & 7 \\
\hline Variada & 5,6 & 36,1 & 15,3 & 32,7 & 9,3 & 1 \\
\hline $\begin{array}{c}\text { Educativa- } \\
\text { formativa }\end{array}$ & 2,7 & 17,0 & 16,1 & 41,5 & 21,3 & 1,3 \\
\hline Interesante & 3,6 & 27 & 21,7 & 34,7 & 11,6 & 1,4 \\
\hline $\begin{array}{c}\text { Vulgar, de mal } \\
\text { gusto }\end{array}$ & 15,6 & 40,2 & 21,2 & 15,8 & 4,6 & 2,5 \\
\hline
\end{tabular}

Fuente: Centro de Investigaciones Sociológicas. (CIS) Barómetro de Octubre de 2003 
Por su parte, el presidente del Consejo Audiovisual de Navarra, Ramón Bultó, hizo la siguiente reflexión en relación a la televisión que se está haciendo en España:

“la situación actual se encuentra definida por diversos factores: la crisis y la concentración de la TV de pago; el auge de la 'telerealidad' y las estrategias de 'irradiación' de los programas de éxito; la ausencia de un modelo de TV pública; el peso de las productoras y la debilidad de las marcas de las cadenas; los cambios de accionariado en las TV privadas; y la polémica acerca de la 'telebasura',"10.

En palabras de Cembrano Díaz (2006), la televisión se inclina por emitir ciertos contenidos que se muestran en la siguiente tabla:

\footnotetext{
${ }^{10}$ XVIII Congreso Internacional 'Ecología de la televisión, tecnología, contenidos y desafíos empresariales', celebrado en la Universidad de Navarra el 6 y 7 de noviembre de 2003. Fuente: Revista Digital de la Fundación audiovisual de Cataluña: http://www.fundacionava.org/pages/revista.php?page=1\&id=365
} 
Tabla 2:

'Opciones que elige la televisión al momento de emitir'

\begin{tabular}{|c|c|}
\hline $\begin{array}{c}\text { Es más fácil } \\
\text { televisar... }\end{array}$ & Que... \\
\hline Lo simple & Lo complejo \\
\hline Los efectos & Las causas \\
\hline Lo concreto & Lo abstracto \\
\hline Lo individual & Lo colectivo \\
\hline La competición & La cooperación \\
\hline Lo extravagante & Lo común \\
\hline Los hechos & Las relaciones \\
\hline Lo que se tira & Lo que dura \\
\hline Los sucesos & Los procesos \\
\hline Los datos & $\begin{array}{c}\text { El significado de los } \\
\text { datos }\end{array}$ \\
\hline Las conductas & $\begin{array}{l}\text { Los motivos de las } \\
\text { conductas }\end{array}$ \\
\hline La tensión & La articulación \\
\hline $\begin{array}{l}\text { Las relaciones } \\
\text { mecánicas }\end{array}$ & $\begin{array}{l}\text { Las relaciones } \\
\text { orgánicas }\end{array}$ \\
\hline Los líderes & Los pueblos \\
\hline Los excluidos & La exclusión \\
\hline La fuerza & La razón \\
\hline Los productos & $\begin{array}{c}\text { La contaminación que } \\
\text { producen }\end{array}$ \\
\hline La jerarquía & $\begin{array}{c}\text { La democracia } \\
\text { participativa }\end{array}$ \\
\hline El consumo & El no consumo \\
\hline
\end{tabular}

Fuente: Cembranos Díaz, www.aideka.tv, 18/10/2006 


\section{En búsqueda de la regulación televisiva}

Desde sus comienzos, la regulación televisiva ha sido objeto constante de control e intervención por parte del poder estatal; un poder centralizado que gestionó la televisión en régimen de monopolio bajo el modelo de 'servicio público'.

Por ende, la 'regulación' se constituyó como el sistema de ordenamiento de los primeros años de la televisión ${ }^{11}$, constituyéndose como la forma más tradicional y de antaño en cuanto a técnicas legislativas se refiere, donde el poder y las decisiones estatales eran las vertientes que dirigían el ordenamiento jurídico del sector, que sentarían las bases que regirían a la radio y a la televisión en España.

Para entender en su conjunto el proceso regulativo español, es necesario remontarse, en primer lugar, a la desregulación televisiva sufrida en los países europeos en la década de los 80's, motivada por la iniciativa estatal de privatizar la televisión, lo que permitió la concesión de nuevas licencias a gestores privados.

Esa descentralización del poder televisivo ocasionó un aminoramiento en la reglamentación de las cadenas como servicio público (Alonso, 1995: 14), lo que se tradujo en una baja en la calidad en los contenidos televisivos, al tiempo que se forjaron nuevas formas, mucho más comerciales y similares al modelo estadounidense, de concebir y hacer televisión.

A raíz de estos cambios, la historia legislativa de la televisión en España recoge diversos intentos por concienciar a las empresas audiovisuales de su función social y de las repercusiones que genera el hecho de emitir contenidos, sobre todo para los públicos más vulnerables; por ende las reacciones, por iniciativa del Estado, no se han hecho esperar.

A partir de la década de los 90's, la 'autorregulación' y la ‘corregulación' comenzaron a considerarse como vías alternativas de control consensuado en donde, tanto los propietarios de las cadenas como el gobierno, firmaron varios acuerdos en pro de mejorar la calidad televisiva.

\footnotetext{
${ }^{11}$ El 'Estatuto de la Radio y la Televisión', Ley 4/1980, de 10 de enero, fue la primera reglamentación creada para el ordenamiento de los medios de comunicación en España.
} 
Ejemplo de ello lo fue el 'Convenio para la autorregulación de la emisión de contenidos violentos, discriminatorios y $\operatorname{sexistas}^{12}$, (1993), el 'Sistema uniforme de señalización de la clasificación de los programas de televisión'13 (1999) en función de su grado de idoneidad para los menores, el 'Código de Corregulación' y el 'Código de Autorregulación para los contenidos televisivos e infancia' (2004), que dieron lugar al 'Comité de Autorregulación' y la 'Comisión Mixta de Seguimiento'. A estas últimos se les adjudicó la función de hacer cumplir lo ordenado en dicho código y donde se cuenta con la participación de algunas organizaciones sociales ${ }^{14}$, propuestas del gobierno socialista.

Las medidas antes descritas fueron tomadas debido a que se consideró que alrededor de este tema existía 'una cierta alarma social' por los contenidos que se emitían ${ }^{15}$. Desde entonces la televisión comenzaba a ser un malestar social en el que había que dar respuestas. Motivado por la situación del sector audiovisual, también fue implementada la 'Comisión Especial sobre los contenidos televisivos' (1993-1995) ${ }^{16}$, por iniciativa del Senado.

Por último, y en relación a la televisión pública, se propuso a un 'Comité de Sabios ${ }^{17}$, para que elaborara un informe que sentara las bases de una nueva ley para los medios audiovisuales. Asimismo este grupo discutió, entre otros temas, sobre la creación de un 'Consejo Estatal de Medios Audiovisuales ${ }^{18}$.

\footnotetext{
${ }^{12}$ Este código deontológico, pese a que logró su propósito de reunir a los propietarios de las cadenas de televisión con el objetivo de que asumieran la responsabilidad educativa del medio, en un contexto de fuerte competitividad y desregulación en el mercado, no tuvo carácter legal, sólo moral (Rico, 1994: 141-142, 174).

${ }^{13}$ Se estableció con la finalidad de proteger al telespectador y redimir su derecho a estar informado sobre los contenidos que se emitían.

${ }^{14}$ Ambos códigos fueron firmados, por las tres televisiones generalistas (broadcasting) que emiten en abierto en España, Antena 3, Telecinco y Televisión Española.

15 Palabras de la Vicepresidenta Primera del Ejecutivo, María Teresa Fernández de la Vega, (http://actualidad.wanadoo.es, 26/10/2004. Agencia EFE).

${ }^{16}$ Constituida el 20 de diciembre de 1993, finalizando sus trabajos el 15 de noviembre de 1995, que tuvo como objetivo valorar en estado de la televisión y de los contenidos, y reflexionar sobre las posibles líneas de acción para su mejora.

${ }^{17}$ En el plazo de 9 meses desde su constitución, el consejo dará traslado de su informe como propuesta al gobierno para su posterior 'traducción en las disposiciones normativas que permitan hacer efectivo su contenido' (www.elmundo.es, jueves 13 de mayo de 2004, agencia EFE).

${ }^{18}$ Esta es una petición que las asociaciones de telespectadores llevan años proponiendo.
} 
Pese a las medidas anteriormente implementadas, en el panorama actual de los contenidos de la televisión la constante prevaleciente es el interés económico, hecho que ha obstaculizado el proceso de regulación que se viene llevando a cabo desde hace varios años.

De acuerdo a Reig (2006: 98), las televisiones privadas han logrado beneficios a costa de:

- Traspasar los límites legales de las emisiones de publicidad

- Abaratar los costes de los medios de producción

- Renunciar a programaciones culturales y a programación infantil y juvenil

- Emitir programación de audiencia asegurada sin preocuparse lo más mínimo de la expresión del significado de servicio público, tomada como elemento de formación, no de creación y fortalecimiento de las zonas más elementales de los instintos humanos

- Hacer pasar por información y periodismo noticias que son publicidad encubierta

- Sacrificar los informativos en pro del espectáculo

Lo económico es tan fuerte que las empresas audiovisuales han evadido cualquier intento que pudiera significarles algún cambio en su funcionamiento interno, pese al compromiso asumido, por su parte, en la firma de acuerdos y códigos, respaldándose bajo el derecho a su libertad de expresión, de iniciativa y de mercado, cuestión que viene sucediendo desde las primeras legislaciones televisivas, incluyendo las más recientes normativas que se han impuesto a nivel Europeo ${ }^{19}$.

\footnotetext{
${ }^{19}$ Ley de 'Televisión sin Fronteras'.
} 


\section{Los grupos organizados: rompiendo los paradigmas televisivos}

Dentro de este contexto legislativo y donde las relaciones de poder entre los diferentes agentes de la comunicación (Estado, anunciantes, productoras independientes y cadenas de televisión, grupos de comunicación) han sido insoslayables, diferentes grupos organizados en asociaciones de telespectadores y ONG' s vienen promoviendo acciones encaminadas a la mejora de los contenidos que emiten las televisiones generalistas abiertas en España, logrando hacerse presentes en el ámbito televisivo, con el fin de servir de contrapeso en la balanza de intereses del mercado audiovisual y de sus principales actores.

\section{Esquema 1:}

'Cadena de valor del sector audiovisual'

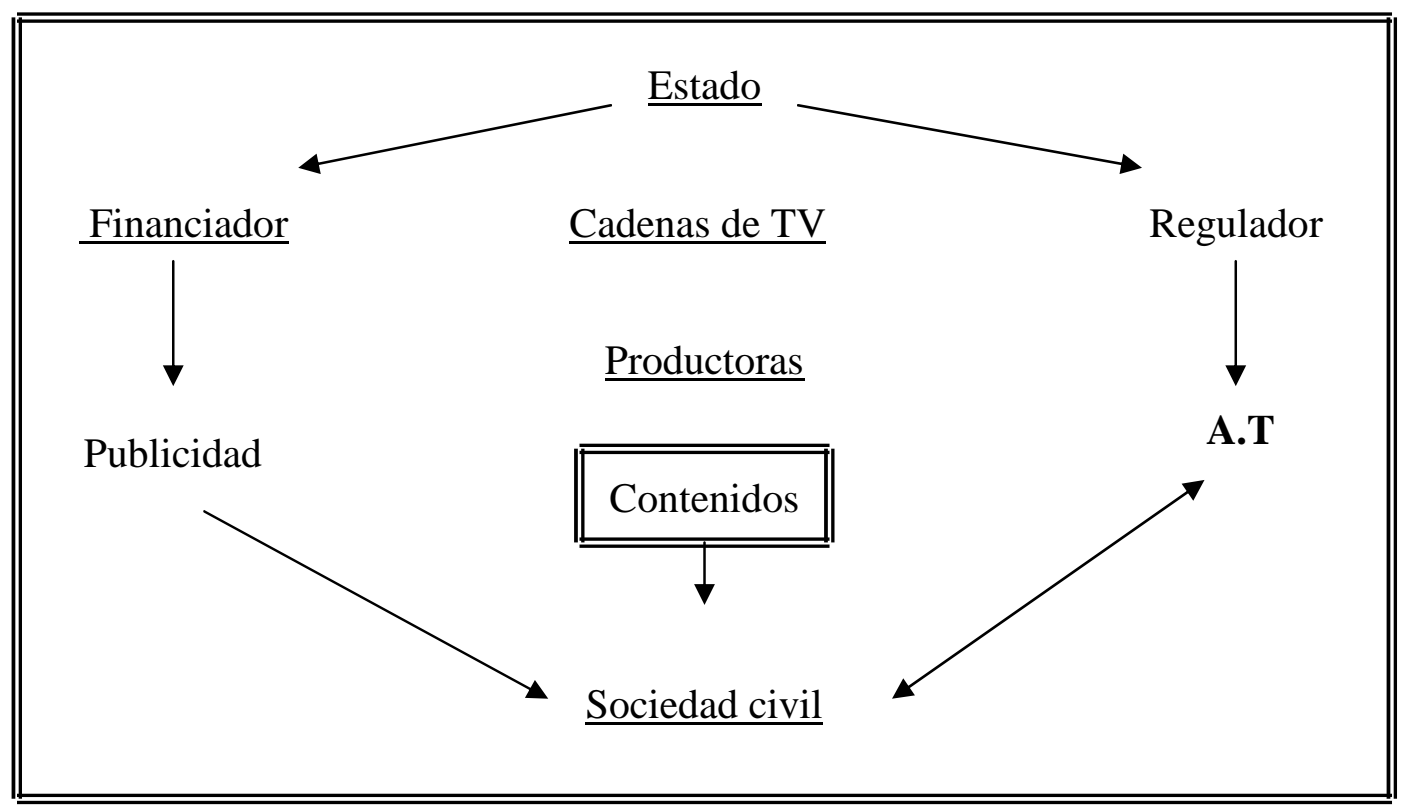

Nota: Elaboración propia 
Las 'asociaciones de telespectadores' nacieron en la década de los $80^{20}$ como producto de una iniciativa de ley que las consideró como posibles colaboradoras de los 'Consejos Asesores' ${ }^{21}$. Desde entonces han basado su ejercicio en la defensa de los usuarios de la televisión, promoviendo la ‘educación para los medios', constituyéndose así como grupos contestatarios ante una dinámica televisiva que se ha venido mostrando indiferente en relación a los derechos del ciudadano telespectador.

El renacer de estas asociaciones se hizo presente con la entrada de las televisiones privadas en los 90's, momento histórico en el que despega la televisión comercial en España y con ella, desajustes e inconformidades cara a una televisión que comenzaba a hacer patentes indicios de irregularidades en torno a lo normativo y a la programación, así como disparidades entre lo que la sociedad española esperaba de su televisión.

En ese resurgimiento, que podríamos identificar con el verdadero auge de este movimiento social, comienzan a nacer asociaciones tales como la 'Asociación de Usuarios de la Comunicación' (AUC, 1983), que actualmente constituye una de las más importantes en España junto con la 'Agrupación de Telespectadores y Radioyentes' (ATR, 1985), la 'Federación Ibérica de Asociaciones de Telespectadores y Radioyentes' (FIATRY, 1992) que agrupa a más de 17 asociaciones repartidas por el territorio español y portugués, y finalmente el 'Foro del Espectador' (2003).

\footnotetext{
${ }^{20}$ Data en este año la inscripción en el Registro Nacional de Asociaciones en el Ministerio del Interior, de la 'Primera Asociación Española de Espectadores de Televisión’ en España (1980).

${ }^{21}$ Con el objetivo expreso de que la sociedad civil tuviera representación en la primera ley para los medios de comunicación, (Ley 4/1980, de 10 de enero, de Estatuto de la Radio y la Televisión), se plasmó la importancia de la creación de 'asociaciones de telespectadores', sin embargo, esta iniciativa quedó reflejada sólo en el papel.
} 
Tabla 3:

'Asociaciones de telespectadores españolas'

\begin{tabular}{|c|c|}
\hline Asociaciones de Telespectadores españolas & $\begin{array}{l}\text { Ubicación } \\
\text { geográfica }\end{array}$ \\
\hline $\begin{array}{l}\text { ACTR Asociación Canaria de Telespectadores y } \\
\text { Radioyentes }\end{array}$ & $\begin{array}{l}\text { Islas } \\
\text { Canarias }\end{array}$ \\
\hline $\begin{array}{l}\text { ACUMECO }^{22} \text { Asociación de Consumidores y Usuarios } \\
\text { de Medios de Comunicación }\end{array}$ & Jaén \\
\hline *** AJT Asociación de Jóvenes Telespectadores & Valencia \\
\hline $\begin{array}{l}\text { *ATELEUS Asociación de Telespectadores del País } \\
\text { Vasco }\end{array}$ & País Vasco \\
\hline $\begin{array}{l}\text { *ATERGA GALICIA Asociación de Telespectadores } \\
\text { y Radioyentes de Galicia }\end{array}$ & La Coruña \\
\hline *ASUmME Asociación de Usuarios de Mass-Media & Murcia \\
\hline *ATR- ALICANTE & Alicante \\
\hline *ATR-ANDALUCÍA & Granada \\
\hline *ATR- ASTURIAS & Oviedo \\
\hline *ATR- BURGOS & Burgos \\
\hline *ATR-CANTABRIA & Santander \\
\hline *ATR- CIUDAD REAL & Ciudad Real \\
\hline ATR- CORUÑA & La Coruña \\
\hline ATR- JAËN & Jaén \\
\hline ATR- NAVARRA & Pamplona \\
\hline ATR- PONTEVEDRA & Pontevedra \\
\hline *ATR- SALAMANCA & Salamanca \\
\hline ATR- VALLADOLID & Valladolid \\
\hline ATRA Asociación de Telespectadores y Radioyentes de & Zaragoza \\
\hline
\end{tabular}

${ }^{22}$ Debido a su reciente creación, estudian la posibilidad de llamarse ‘ATR Jaén’ (ATR, 2006 b: 4). 


\begin{tabular}{|l|c|}
\hline Aragón & \\
\hline AUC Asociación de Usuarios de la Comunicación & Madrid \\
\hline $\begin{array}{l}\text { EURALVA }^{\mathbf{2 3}} \text { European Alliance of Listeners and } \\
\text { Viwers Associations }\end{array}$ & Unión Europea \\
\hline $\begin{array}{l}\text { FIATYR Federación Ibérica de Asociaciones de } \\
\text { Telespectadores y Radioyentes }\end{array}$ & $\begin{array}{c}\text { España } \\
\text { Potugal } \\
\text { Andorra }\end{array}$ \\
\hline FORO DEL ESPECTADOR & Madrid \\
\hline TAC Telespectadores Asociados de Cataluña & Cataluña \\
\hline *TRAB Telespectadores y Radioyentes Asociados de & Islas Baleares \\
Baleares & Valencia \\
\hline *TRAV Telespectadores y Radioyentes Asociados de & \\
\hline
\end{tabular}

Fuente: Elaboración propia a partir de los datos proporcionados por la Agrupación de Telespectadores y Radioyentes (ATR) y de sus boletines mensuales: 'ATR Noticias' (09-07-2004) (*) Asociaciones que forman parte de FIATYR

Pese a ello, otras organizaciones sociales que persiguen fines similares tal y como la protección de la infancia y la juventud, han sido también partícipes en esta problemática ${ }^{24}$. Tal es el caso de la 'Confederación Española de Asociaciones de Padres y Madres de Alumnos' (CEAPA), la ‘Confederación Católica Nacional de Padres de Familia y Padres de Alumnos’ (CONCAPA), el 'Consejo de Consumidores y Usuarios' y la 'Plataforma de Organizaciones de Infancia', todas ellas miembros y partícipes en la 'Comisión Mixta de Seguimiento' del 'Código de Autorregulación para los contenidos televisivos e infancia'.

${ }^{23}$ La Federación Ibérica de Asociaciones de Telespectadores y Radioyentes (FIATYR) forma parte de EURALVA (European Alliance of Listeners and Viwers Associations)

${ }^{24}$ La UNICEF-Comité Español, las Comisiones Obreras, el Observatorio Europeo de Televisión Infantil (OETI), la Confederación de Consumidores y Usuarios (CECU), la Federación de Asociaciones la Prensa en España (FAPE), la Federación Católica de Asociaciones de Padres de Familia y Padres de alumnos de Madrid, la Federación Regional de Asociaciones de Vecinos de Madrid (FRAVM), la Federación Regional de Madrid de Asociaciones de Padres y Madres del alumnado 'Francisco Giner de los Ríos', la Organización de Consumidores y Usuarios (OCU), la Unión General de trabajadores (U.G.T. Madrid), el Defensor del Menor en la Comunidad de Madrid, entre otros, apoyan el movimiento asociativo en pro de mejorar la televisión. 
Cabe destacar que con el cambio de gobierno nacional (2004) el debate social en torno a los contenidos se intensificó donde se hizo patente un 'avance, 25 para estos grupos, ya que los socialistas llegaron con iniciativas, recogidas muchas de ellas de los distintas organizaciones civiles antes mencionadas, que pusieron en práctica, tal como el 'Consejo Estatal de Medios Audiovisuales', organismo que existe en casi todos los países de la Comunidad Europea ${ }^{26}$ y que había sido propuesto desde hace años por estas asociaciones.

El 'Defensor del Telespectador', es otra figura creada por la televisión pública andaluza en $1995^{27}$, que también actúa como mediador entre la ciudadanía y las empresas audiovisuales, atendiendo las quejas y sugerencias de los telespectadores sobre los contenidos de la televisión, además de promover el conocimiento y la formación de la audiencia. Asimismo vigila las normas básicas de programación y publicidad y los derechos que amparan a los ciudadanos respecto a los medios de comunicación (Sánchez Apellániz, 1996: 71).

Por otra parte, los 'Consejos Audiovisuales' 28 han tenido, a nivel local, una importante función en la tarea de mantener regulada a su televisión, ejerciendo la función de 'observatorio de los medios', encargados de vigilar y estar al tanto de las acciones de las empresas audiovisuales y los anunciantes, principalmente, y quienes a través de las investigaciones que realizan, dan a conocer las múltiples infracciones que cometen las cadenas de televisión en su ejercicio diario.

\footnotetext{
25 "En un plazo record, el PSOE mantuvo contacto con las asociaciones de telespectadores, cosa que el gobierno anterior no había hecho durante su mandato. De repente, lo que veníamos denunciando durante tanto tiempo era muy justo para todo el mundo (...)." (Asociación Plaza del Castillo, 2005.) Sin embargo, sólo algunos grupos fueron considerados para formar parte de la 'Comisión Mixta de seguimiento' del 'Código de autorregulación para los contenidos televisivos e infancia', aunque quedaron excluidas específicamente las asociaciones de telespectadores.

${ }^{26}$ Ejemplos a destacar son el 'Conseil Supérieur de l'Audiovisuelle' en Francia, el 'Independent Televisión Comission' en el Reino Unido, 'Il Garante' en Italia, la 'Comisión Independiente de Radio y Televisión' en Irlanda, el 'Consejo Supremo de la Radio y la Televisión' en Turquía, la 'Alta Autoridad de la Comunicación Social' en Portugal, el 'Comisariíta loor de Media' en los Países Bajos, el 'Consejo Nacional de Radiotelevisión' en Grecia, el 'Consejo de la Radiotelevisión Canadiense', la 'Federal Communication Comission' en Estados Unidos, la 'Australian Broadcasting Tribune’ en Australia, etcétera (Senado, 1996).

${ }^{27}$ En ese año sólo la televisión canadiense contaba con una figura similar (Casado, 1997: 101).

${ }^{28}$ Hoy en día destacan el 'Consejo Audiovisual de Cataluña', el 'Consejo Audiovisual de Navarra', el 'Consejo Audiovisual de Andalucía' y se está a la espera de la creación del 'Consejo Audiovisual de Madrid', todos con capacidad sancionadora a nivel local.
} 
Para concluir este apartado, cabe destacar la siguiente reflexión: “el único límite real al poder de la televisión son sus audiencias, a las que hay que despabilar, movilizar y acompañar" (Orozco, 2001: 15).

\section{Conclusiones}

Es un hecho que al paso de los años, organizaciones civiles de diferentes regiones de España vienen emergiendo en torno a los temas de la televisión con orientaciones y fines diversos, quienes poco a poco han ido tomando fuerza y han encontrado vías claras para operar y ejercer sus funciones. Todas ellas con el propósito de incidir en la manera cómo se estructuran las políticas televisivas relacionadas con los contenidos, y con el objetivo de cumplir su función social respecto a los ciudadanos telespectadores, proporcionándoles herramientas a través de la 'educación audiovisual' para que pueda tener una actitud crítica y activa ante los medios de comunicación.

Con el tiempo, su activismo las ha ido convirtiendo en una voz representativa y legítima de la conciencia de sus comunidades y están logrando ciertos cambios en los escenarios televisivos, en particular sobre el tema de los contenidos de televisión generalista ${ }^{29}$.

Pese a ello, lo que cabe destacar es que lo que estamos viviendo fuertemente en esta etapa de transición es la era del grupismo. Construimos grupos defensivos que afirman su identidad en torno a la solidaridad y lucha por sobrevivir junto con y en contra de otros grupos (Wallerstein, 2003: 7-8), lo que exime a generalizar que estos organismos civiles puedan considerarse como 'representantes de la sociedad civil en su conjunto.'

\footnotetext{
${ }^{29}$ Al hablar de que la ciudadanía incide en las políticas televisivas, ya sean las políticas que el gobierno formula para que sean observadas y ejecutadas por las cadenas, sean públicas o privadas, o las que diseñan directamente las cadenas para gestionar su programación, se puede decir que se está iniciando un cambio cualitativo en la forma de hacer televisión, pues se está pasando de una política meramente gubernamental a una propiamente dicho política pública, en la medida en que se toma en cuenta el punto de vista de la ciudadanía. La acción pública solo aparece en donde operan los sistemas democráticos; la acción no es pública sólo porque sea una acción gubernamental. "La participación es el valor democrático por excelencia que promueve la colaboración ciudadana en la formulación y en la implantación de la acción pública" (Bañón, 2003: XVIII).
} 
La importancia de las asociaciones de telespectadores radica en sí, en la figura que representan. Su función como intermediarios o mediadores dentro de la estructura de poder del sector audiovisual es su mayor virtud, ya que la fuerza que detenta el Estado, las empresas audiovisuales, los grupos de comunicación y los anunciantes, ha desvelado, desde los orígenes de la televisión, un discurso unidireccional en donde el ciudadano telespectador no ha tenido vía alguna para escalar esta pirámide, quedando siempre relegado a una posición marginal.

La 'legitimidad' de las asociaciones está condicionada en gran parte, por la propia sociedad civil, ya que en ella se encuentran las raíces que pueden hacer crecer este movimiento social. Por ende, la mayor arma de estos grupos es la ‘comunicación' a través de la cual deben dar a conocer sus fines en pro de alentar a la participación ciudadana y no, por el contrario, el desconocimiento y el rechazo.

Al respecto, una muestra piloto aplicada a una muestra aleatoria de ciudadanos españoles, arrojó que sólo uno de cada cinco ciudadanos españoles sabe de la existencia de estas asociaciones, pero, por otra parte, casi nueve de cada diez consideran que podrían desempeñar una función importante respecto a la televisión ${ }^{30}$.

Otros factores clave que pueden traer cambios en la programación televisiva española están, por una parte, en la composición final que tendrá el 'Consejo Estatal de Medios Audiovisuales' donde cabe esperar qué grupos y organismos civiles serán considerados para formar parte, y por otra, en la adecuación entre la teoría y la práctica que se lleve a cabo al momento iniciarse las actividades de este Consejo y, posteriormente, la evaluación de su funcionalidad.

A pesar de la situación tan compleja y no tan alagüeña aquí expuesta, me quedo con esta reflexión ciudadana: “las imágenes serán lo que decidamos que sean” (Aguilar, 2000).

\footnotetext{
${ }^{30}$ Se trata de avances de investigación de campo que realicé en diferentes provincias con fines académicos.
} 


\section{Referencias}

AGUILAR, P. 2000. Manual del telespectador inteligente. Fundamentos, Madrid.

ALONSO, M. 1995. «La programación infantil tras las televisiones privadas », Cuadernos de Pedagogía, 241, pp. 2-23.

ASOCIACIÓN PLAZA DEL CASTILLO 2005. Medios de Comunicación Social en 2005. Una situación enrevesada, Asociación Plaza del Castillo, Usuarios de Medios de Comunicación.

BAÑÓN I MARTÍNEZ, R. 2003. La evaluación de la acción y de las políticas públicas. Díaz de Santos, Madrid.

CASADO, J. M 1997. "La responsabilidad educativa de la televisión”, La otra mirada a la tele. Propuestas para un consumo inteligente de la televisión, Consejería de Trabajo e Industria, pp. 97-103, Sevilla.

DÍAZ, L. 1999. Informe sobre la televisión en España 1989-1999., Grupo Zeta, Barcelona. ECO, U. 2003. Apocalipticos e integrados. Tusquets, Barcelona.

HEROUVILLE, Y. e Isabelle Gougenheim. 2001. La télévision, Le cavalier bleu, París. JOST, F. 2002. L'empire du loft. La Dispute, París.

LAFFOND, Rueda, J. C. et. al. 2005. Imágenes y palabras, medios de comunicación y públicos contemporáneos., Centro de Investigaciones Sociológicas (CIS), Madrid.

MARCUSE, H. 1968. El hombre unidimensional. Joaquín Motriz, México.

MCLUHAN, M. y Quentin Fiore, 1967. The Medium Is the Massage: An Inventory of Effects, Bantam Books, Nueva York.

RICO, L. 1994. El buen telespectador: cómo ver y enseñar la televisión. Espasa Calpe, Madrid.

REIG, R. 1998. Medios de comunicación y poder en España, prensa, radio, televisión y mundo editorial. Paidós, Barcelona. 
SÁNCHEZ APELLÁNIZ, M. J. 1996. "La nueva figura del defensor del telespectador", Comunicar 7, pp. 68-72, Huelva.

SARTORI, G. 1997. Homo Videns. Taurus, Madrid.

SECRETARÍA GENERAL DEL SENADO, 1996. Informe de la Comisión Especial sobre Contenidos Televisivos, Dirección de Estudios y Documentación, Servicio de publicaciones del Senado, Madrid.

WALLERSTEIN, I, 2003. Después del liberalismo. Siglo XXI y el Centro de Investigaciones Interdisciplinarias en Ciencias y Humanidades, UNAM, México. 
